
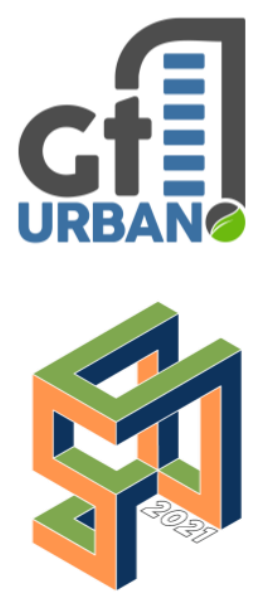

SINGEURB

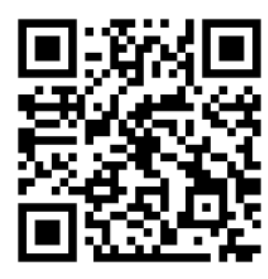

Como citar:

CARVALHO, Liliane

Katita. Territórios

vulneráveis e

equipamentos

culturais oficiais:

Uma análise sobre os

vínculos espaciais no

município de São

Paulo. In: III

SIMPÓSIO

NACIONAL DE

GESTÃO E

ENGENHARIA

URBANA:

SINGEURB, 2021,

Maceió. Anais...

Porto Alegre:

ANTAC, 2021. p. 517-

524.

Disponível em:

https://eventos.antac.

org.br/index.php/sin

geurb/issue/view/14

\section{Territórios vulneráveis e equipamentos culturais oficiais: Uma análise sobre os vínculos espaciais no município de São Paulo}

\author{
Vulnerable territories and official cultural \\ equipment: An analysis of spatial links in the city \\ of São Paulo
}

Liliane Katita Carvalho, Universidade Federal do ABC, 1.katita@ufabc.edu.br

\section{RESUMO}

Este artigo busca evidenciar vínculos existentes entre determinados equipamentos culturais oficiais e territórios vulneráveis do município de São Paulo, através da aplicação de técnicas do geoprocessamento. Espera-se, através desta análise, corroborar para o entendimento espacial do conjunto de equipamentos culturais oficiais da cidade, no entendimento de suas classificações e as relações resultantes desta dinâmica no território. Para a identificação dos territórios vulneráveis destacase o Índice Paulista de Vulnerabilidade Social - IPVS produzido pelo SEADE, bem como, os dados catalogados e disponibilizados pela Prefeitura do Município de São Paulo a respeito do território e dos equipamentos culturais da cidade. Pretende-se identificar as áreas do município que concentram o maior e o menor número de equipamentos culturais oficiais, a localização dos equipamentos públicos e privados, a relação com a estrutura socioeconômica municipal e, com isso, averiguar como a atual conjuntura de implantação destes espaços afeta a dinâmica do território ao tratarmos das oportunidades de acesso e de produção das atividades culturais na cidade.

Palavras-chave: Equipamento Cultural, Dados Espaciais, Periferia.

\begin{abstract}
This article seeks to highlight existing links between certain official cultural facilities and vulnerable territories in the city of São Paulo, through the application of geoprocessing techniques. It is hoped, through this analysis, to corroborate the spatial understanding of the set of official cultural facilities in the city, in the understanding of their classifications and the relationships resulting from this dynamic in the territory. For the identification of vulnerable territories, the São Paulo Social Vulnerability Index - IPVS, produced by SEADE, is highlighted, as well as the data cataloged and made available by the Municipality of São Paulo regarding the territory and cultural facilities of the city. It is intended to identify the areas of the municipality that concentrate the greatest and least number of official cultural facilities, the location of public and private facilities, the relationship with the municipal socioeconomic structure and, with this, investigate how the current situation of implementation of these
\end{abstract}


spaces affects the dynamics of the territory when dealing with opportunities for accessing and producing cultural activities in the city

Keywords: Cultural Equipment, Spatial Data, Periphery.

\section{INTRODUÇÃO}

A cultura e o território são temáticas que desenvolvem-se indissociavelmente. Nas duas últimas décadas, houve o crescimento de espaços de promoção de cultura não oficiais - auto organizados, caracterizados como espaços que potencializam práticas alternativas de intervenções e de gestão, em especial, no território periférico (CARVALHO e IMBRUNITO, 2019). Tais espaços estão fortemente vinculados a atividades culturais. No intuito de caracterizar analiticamente os possíveis fatores que promovem o aumento destes espaços culturais não oficiais, buscou-se, através deste artigo, identificar as dinâmicas que envolvem os territórios vulneráveis e os equipamentos culturais oficiais no município de São Paulo, buscando demonstrar a diferentes aspectos da espacialidade do conjunto de equipamentos culturais oficiais da cidade. Parte-se da identificação dos territórios de alta vulnerabilidade do município, da localização dos equipamentos culturais oficiais e a partir disso, dos agenciamentos possíveis entre estes dois atores.

Botelho (2001) afirma que pode-se distinguir a produção cultural da sociedade em duas dimensões: aquela em que ocorre no plano do cotidiano e aquela que ocorre no chamado circuito organizado - onde observamse os processos dos equipamentos culturais oficiais. Por se tratar de um campo com maiores investimentos, a produção cultural do chamado circuito organizado, possui de forma considerável uma maior quantidade de registros técnicos e dados cadastrados passíveis de consulta. Estes resultados organizados podem nortear aspectos políticos e econômicos do planejamento de cidades $\mathrm{O}$ cruzamento de dados junto ao território, como nas análises que serão apresentadas adiante, torna-se uma ferramenta agregadora e essencial para o avanço do entendimento da produção do espaço.

A aplicação do planejamento estratégico nas cidades tornou os equipamentos culturais, peças importantes e desejados por parte dos gestores urbanos. Por um lado, têm-se a ideia de que tal estratégia fortalece a visão do 'novo' e da requalificação de áreas degradadas, por outro, espera-se que tais equipamentos facilitem a arrecadação de capital privado tornando-se um investimento rentável a longo prazo. Recorrentemente, nota-se que aplicação desta estratégia se dá em territórios já favorecidos - por infraestruturas de diversas categorias - potencializando, assim, a atração de capital para estas áreas em detrimento aos territórios vulneráveis da cidade. Este processo, como posto em diversos estudos acadêmicos, eleva as condições de desigualdade do meio urbano e as disparidades de localização dos equipamentos culturais pelo território (ALBINATI, 2008). Diante disso, percebemos que a relação entre equipamentos culturais e cidades é complexa e envolve camadas de diferentes áreas do conhecimento. 


\section{Figura 1 - Localização do município de São Paulo}

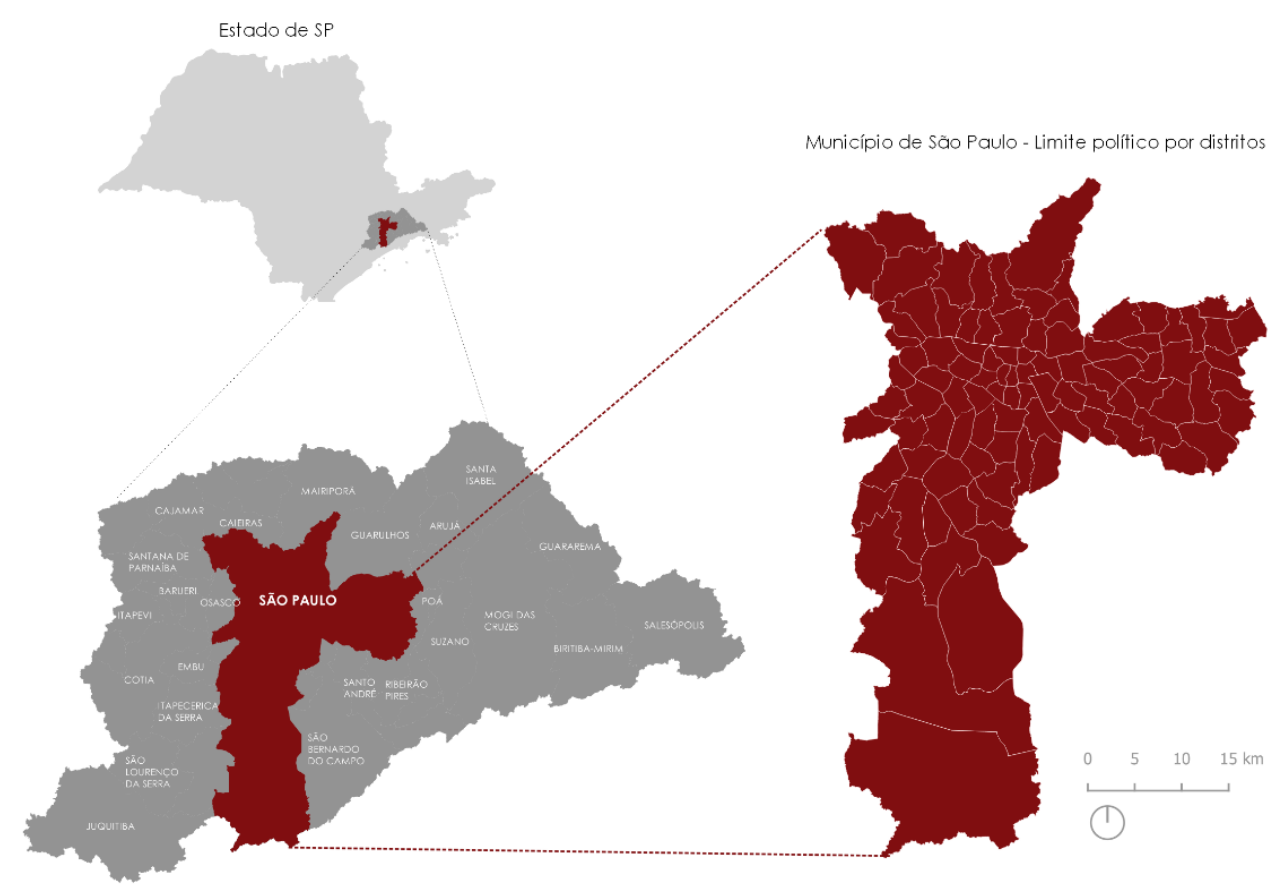

Fonte: Geosampa, 2021. DATUM: SIRGAS 2000 - UTM 23S, elaboração própria.

\section{DADOS ESPACIALIZADOS NO TERRITÓRIO: ANÁLISES E OBSERVAÇÕES}

No município de São Paulo, as relações entre cultura e território são demasiadamente diversificadas, bem como os espaços disponíveis para sua produção e catalogação. Torna-se importante ressaltar que as análises a seguir estão pautadas pelo uso de dados georreferenciados de diferentes temáticas justapostos a localização dos equipamentos de cultura oficiais, tratam-se de informações cadastrados em banco de dados público, disponibilizados pelo poder municipal. Tais informações foram cadastradas de 2003 a 2014, sendo acompanhados pela Secretaria municipal de cultura, somando-se 463 equipamentos culturais oficiais observados por este artigo. Como será demonstrado a seguir, a análise de territórios vulneráveis se dá pelo IPVS-20101, que se utiliza dos setores censitários para propor sua classificação de vulnerabilidade ao território. No mapa nota-se que os territórios vulneráveis estão concentrados, em grande parte, nas periferias das regiões leste e sul, enquanto que, os menos vulneráveis estão concentrados na região central. Por isso, as análises, apresentarão os dados distribuídos pelo município, bem como, um recorte dedicado a região central e outro dedicado ao extremo leste da cidade, com intuito de podermos realizar breves comparações acerca das condições do território caracterizado pelas dinâmicas de vulnerabilidade citadas.

${ }^{1}$ O índice Paulista de vulnerabilidade social - IPVS é um índice de análise de dados desenvolvido pela Fundação Sistema Estadual de Análise de Dados - SEADE, órgão vinculado ao Estado de São Paulo com base nas informações do Censo 2010 
Figura 2 - Equipamentos culturais oficiais no município de São Paulo

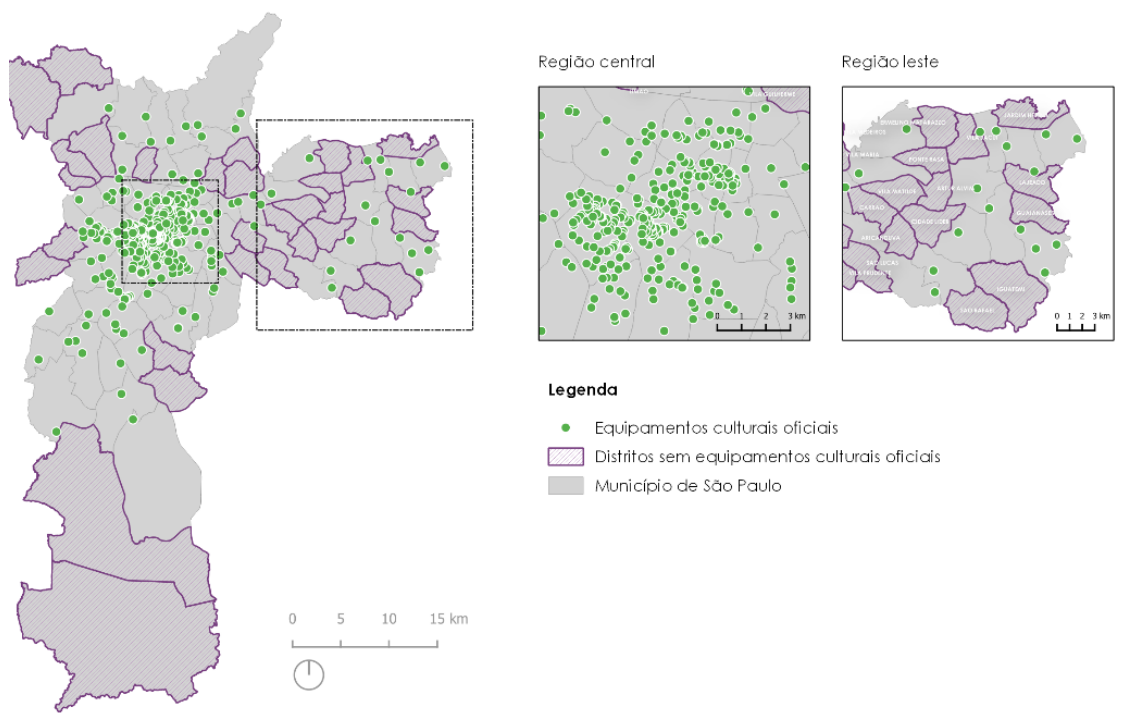

Fonte: Geosampa, 2021. DATUM: SIRGAS 2000 - UTM 23S, elaboração própria.

Ao tratarmos da distribuição dos equipamentos culturais oficiais, destaca-se a implantação desigual pela cidade. A região central, formada por 4 prefeituras regionais, detém 341 dos 463 equipamentos culturais oficiais da cidade. Para as demais 28 prefeituras regionais do município têm-se o total de 122 equipamentos distribuídos. A região leste, formada por 12 prefeituras regionais, apresenta 28 dos equipamentos culturais oficiais, ao considerarmos a região do extremo leste, teremos implantados apenas 15 equipamentos culturais oficiais

Figura 3 - Quantidade de equipamentos culturais oficiais por distrito

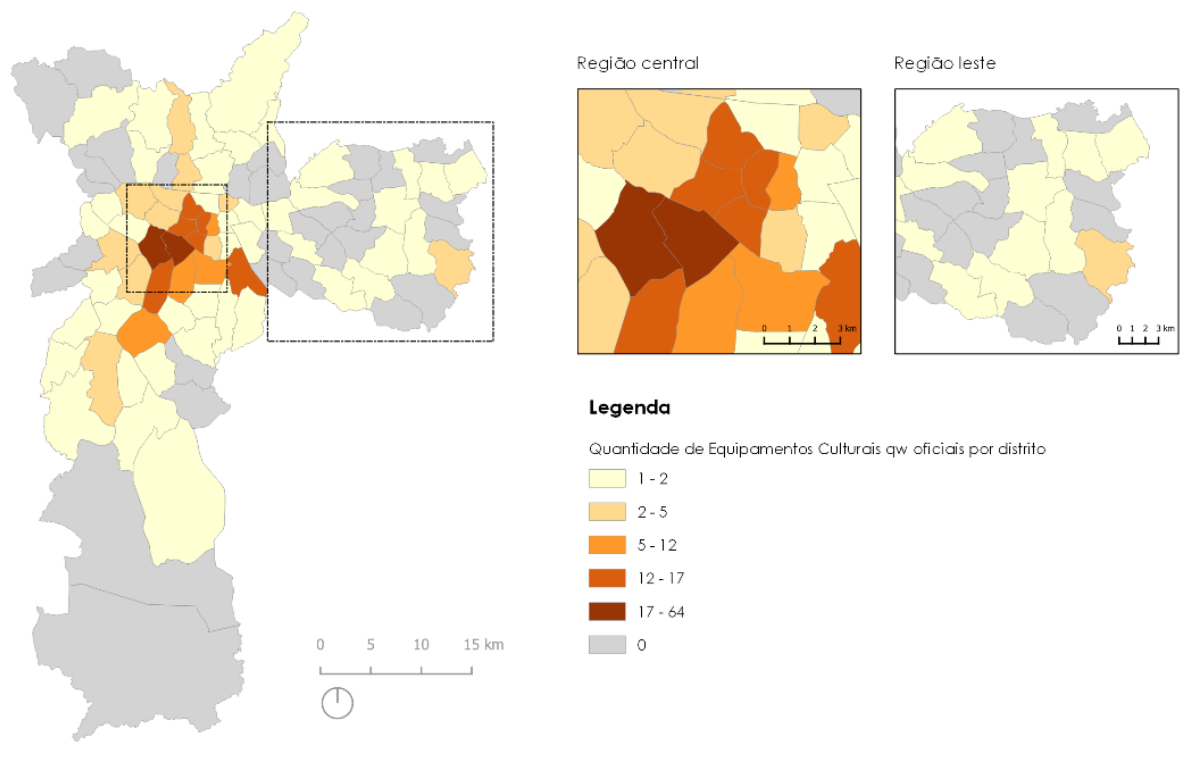

Fonte: Geosampa, 2021. DATUM: SIRGAS 2000 - UTM 23S, elaboração própria. 
Destaca-se a grande concentração de equipamentos nos distritos de Pinheiros e Jardim Paulistano (região central), com 62 e 64 equipamentos respectivamente. Em detrimento, a região da zona leste que apresenta distritos com apenas 1 ou 2, ou nenhum equipamento cultural oficial. Ao compararmos Jardim Paulistano (maior aglutinador de equipamentos da região central) com Cidade Tiradentes (maior aglutinador de equipamentos da zona leste), temos um déficit de aproximadamente 59 equipamentos culturais, um número significativo, que demonstra a grande disparidade de opções quanto a disponibilidade de equipamentos em determinados territórios.

Ao tratarmos da localização dos equipamentos públicos e privados, notamos também disparidades significativas entre os equipamentos classificados como públicos - administrados por uma das esferas municipal, estadual ou federal em relação aos privados - administrados pela iniciativa privada e/ou particular. Dos 463 equipamentos mapeados no município, 311 estão classificados como privados, ou seja, aproximadamente dois terços do total. Enquanto que os classificados como públicos somam 152. Na figura 4 é possível observar o grande conglomerado de equipamentos privados localizados na região central da cidade, nesta área totalizam-se 265 dos 311 equipamentos privados e 61 dos 152 equipamentos públicos do município. Já a região da zona leste apresenta 2 equipamentos privados e 13 equipamentos categorizados como público. Observa no extremo leste uma dinâmica inversa a da região central, pois a maioria dos equipamentos culturais existentes são públicos e não privados, demonstrando a ausência de investimentos privados para dedicados a atividades culturais na região.

Figura 4 - Equipamentos culturais oficiais públicos e privados

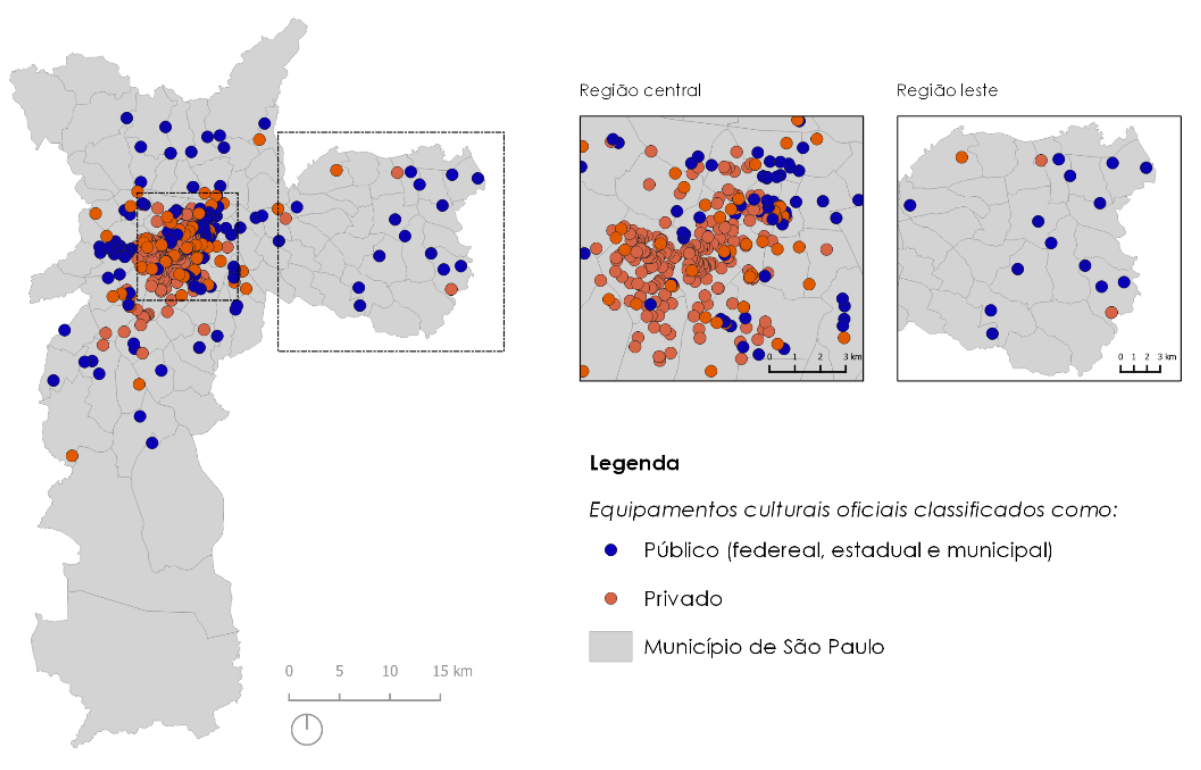

Fonte: Geosampa, 2021. DATUM: SIRGAS 2000 - UTM 23S, elaboração própria.

A figura 5 agrega a localização dos equipamentos culturais oficiais e a classificação de vulnerabilidade do IPVS-2010, tratando da temática do item (iii) relação entre os equipamentos culturais oficiais e a estrutura socioeconômica territorial. Pode-se destacar que no âmbito municipal há, de forma relevante, certa ausência de equipamentos culturais oficiais nas regiões que conglomeram os setores censitários mais vulneráveis, e o inverso é verdadeiro, em que há considerável presença de equipamentos culturais oficiais em regiões consideradas de baixa vulnerabilidade pelo IPVS-2010. Contudo, existem dinâmicas inusitadas como na região central, destacada na figura 07. 
Esta apresenta dualidade nas relações equipamento e território, em que há uma maior parte de seu território classificado como de baixíssima vulnerabilidade, evidenciando-se a prefeitura regional de Pinheiros - área de maior agrupamento de equipamentos culturais, e há na região da prefeitura regional da Sé setores classificados como de muito alta, alta e média vulnerabilidade junto a uma concentração grande de equipamentos culturais oficiais também. Já na região leste destaca-se a ausência de equipamentos culturais no conjunto de setores que conformam um território de vulnerabilidade baixa. Enquanto que o extremo leste, classificado em grande parte como de muito alta e alta vulnerabilidade, apresenta o total de equipamentos culturais oficiais pertencentes à região.

Figura 5 - Localização dos equipamentos culturais oficiais e classificação IPVS-2010 por setor censitário

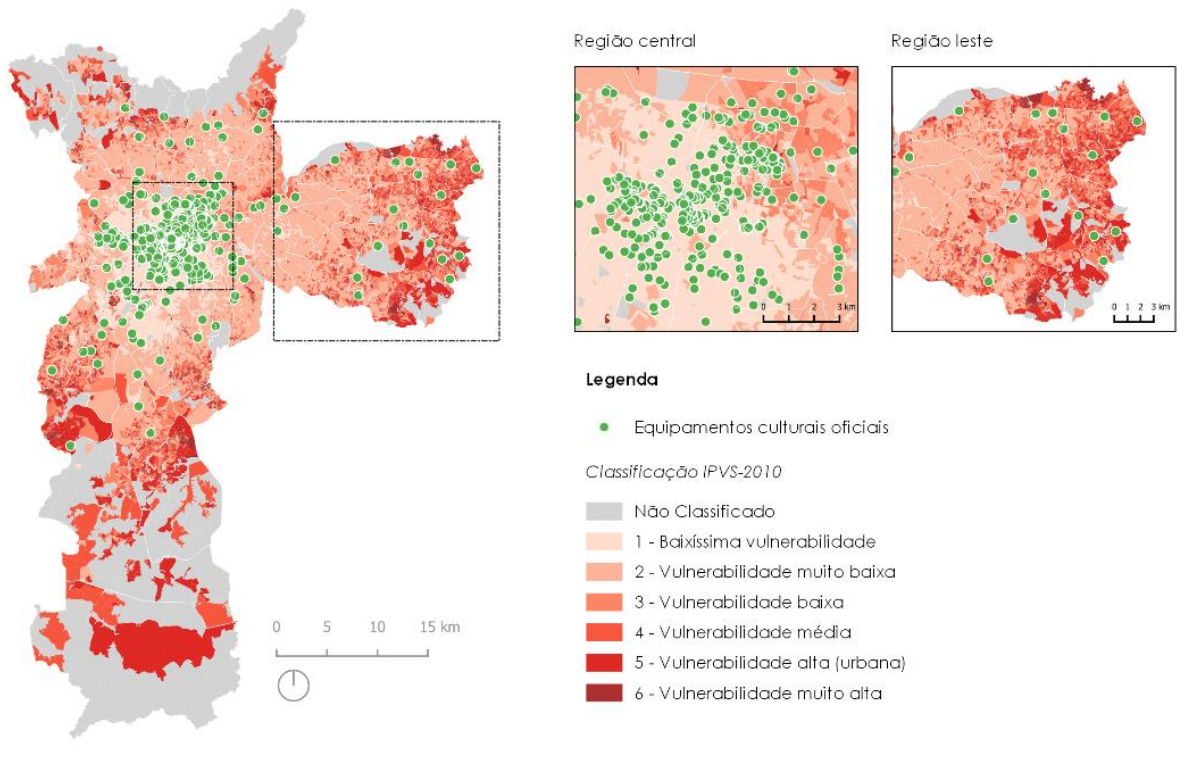

Fonte: Geosampa, 2021. DATUM: SIRGAS 2000 - UTM 23S, elaboração própria.

Tal resultado de análise demonstra que as relações desenvolvidas entre a localização dos equipamentos culturais oficiais e as características socioeconômicas, neste caso de vulnerabilidade, imbrincadas no território são de extrema complexidade. Não necessariamente uma justifica a condição da outra, ou seja, o fato do território ser de alta vulnerabilidade não significa, automaticamente, que ele detenha uma menor quantidade de equipamentos culturais do que áreas de baixa vulnerabilidade. Na Figura 6 pode-se notar fenômeno semelhante, trata-se da relação entre equipamento cultural oficial e a densidade demográfica do município por setor censitário. 
Figura 6 - Localização dos equipamentos culturais oficiais e densidade demográfica por setor censitário

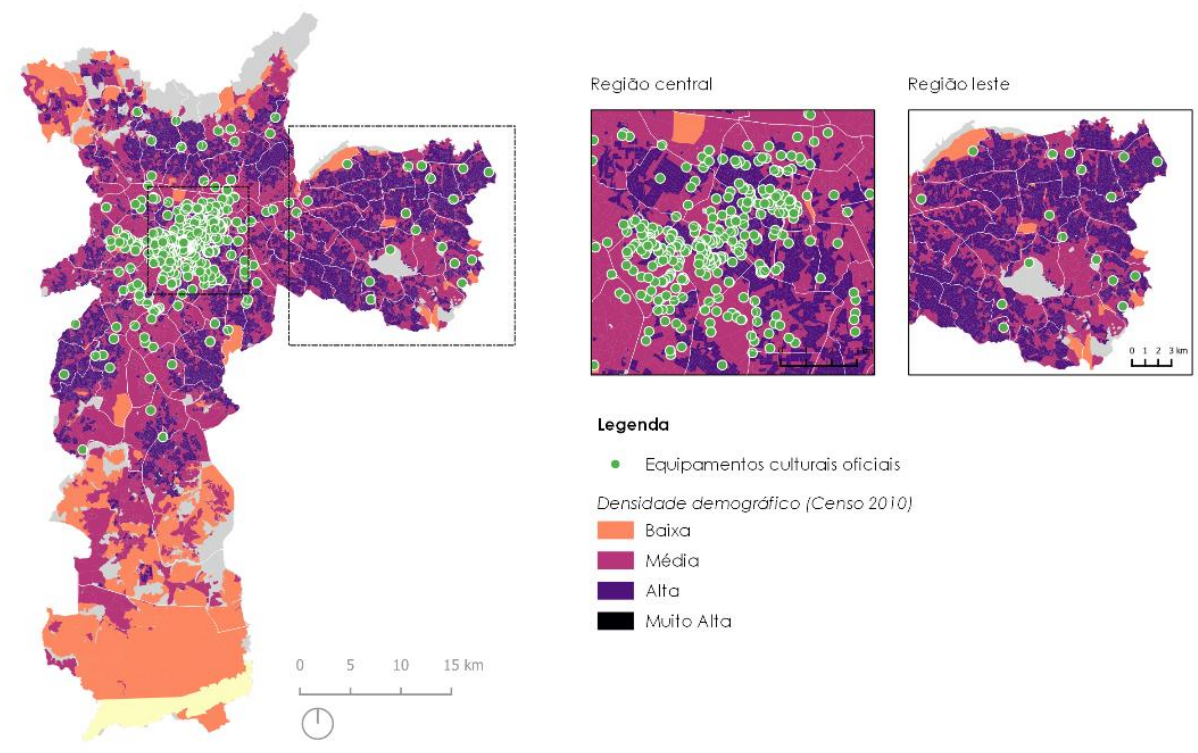

Fonte: Geosampa, 2021. DATUM: SIRGAS 2000 - UTM 23S, elaboração própria.

De maneira geral o município de São Paulo detém uma das maiores densidades demográficas dentre as cidades brasileiras de acordo com os dados do Censo 2010. Nota-se a conformação de áreas que apontam alta densidade, especialmente, nas regiões norte e leste do município. Na região leste, há grande ocorrência de densidade demográfica alta ou muita alta contínua pelo território. Tal característica confronta a quantidade de equipamentos distribuídos pela região em função do número de habitantes, baixo número de equipamentos - muitos habitantes. Ao focarmos na região central, destaca-se a prevalência da densidade classificada como média, demonstrando que a região que detém o maior número de equipamentos culturais não é necessariamente a que detém a maior densidade demográfica do município.

\section{CONCLUSÕES}

Notadamente, percebeu-se que existem diferentes vínculos estabelecidos entre o território e os equipamentos culturais oficiais do município de São Paulo. Grande parte destes vínculos apresentam extrema complexidade e devem ser tratados futuramente junto a dados relevantes da população como suas interações com o equipamento ou porte e capacidade de atendimento do equipamento. Conclui-se que as oportunidades de acesso às atividades de lazer e culturais, através dos equipamentos oficiais, são diferentes em função da região do município. Na região do extremo leste, enfrentam-se entraves que envolvem mobilidade, localização do equipamento, tempo dedicado ao lazer - por se tratar de uma das regiões mais vulneráveis da cidade. Enquanto que a região central do município, apresenta grande quantidade de equipamentos, diversidade de modais disponíveis junto a um a população de baixíssima vulnerabilidade, criando uma atmosfera propicia para o alto aproveitamento dos equipamentos de cultura oficiais.

Atualmente, os processos e técnicas que envolvem o geoprocessamento de dados ganham cada vez mais importância para caracterização e entendimento de qualquer território. Este artigo desenvolveu análises a partir dos dados abertos disponibilizados pelo poder público municipal, estadual e federal, o que não deixa de caracterizar-se com um processo inovador frente a disponibilização dos dados. A cidade possui um 
grande ativo cultural nas periferias que não aparece oficialmente nos dados disponibilizados. Este é um grande desafio da cartografia contemporânea, que está em disputa, quando invisibiliza processos historicamente tradicionais em seus territórios, neste caso, os dados oficializados. A democratização do acesso as técnicas do geoprocessamento podem "colocar no mapa" diferentes percepções do desenvolvimento do território. Tal situação corrobora para que tomadas de decisão no arranjo de políticas públicas que visem sanar demandas e déficits encontrados em analises territoriais, como a deste artigo ou de outros projetos não oficiais que se utilizam de softwares de geoprocessamento de código aberto para a sua produção, amparem melhores soluções do planejamento das cidades e, por consequência, em suas formas de gestão.

\section{REFERÊNCIAS}

ALBINATI, M. L. Cultura e território: equipamentos culturais em bairros populares de salvador. IV ENECULT - Encontro de estudos multidisciplinares em cultura. Salvador: [s.n.]. 2008.

BOTELHO, I. As dimensões da cultura e o lugar das políticas públicas. Revista Perspectiva, São Paulo, v. 15, n. 2, abril/junho 2001. Disponivel em: <https://doi.org/10.1590/S010288392001000200011>. Acesso em: 05 maio 2021.

CARVALHO, L. K.; IMBRUNITO, M. I. Resistências urbanas e sua conjunção em rede: Urban resistances and their network conjunction. Revista Políticas Públicas \&Amp; Cidades - 23591552, São Paulo, v. v.9 n.3, n. n.3, 2019. Disponivel em: $<$ https://rppc.emnuvens.com.br/RPPC/article/view/379>. Acesso em: 06 jun. 2021.

IPVS. Índice Paulista de Vulnerabilide Social. SEADE. São Paulo, p. 18. 2013.

PMSP, PREFEITURA DE SÃO PAULO. GEOSAMPA - Mapa digital da cidade de São Paulo. [S.l.]. (http://geosampa.prefeitura.sp.gov.br/PaginasPublicas/_SBC.aspx). 